\title{
Preseason preparation training and endothelial function in elite professional soccer players
}

\author{
This article was published in the following Dove Press journal: \\ Vascular Health and Risk Management \\ 26 November 2015 \\ Number of times this article has been viewed
}

\author{
Nikolaos E Androulakis' \\ Nikolaos E Koundourakis ${ }^{2}$ \\ Eleni Nioti ${ }^{\prime}$ \\ Paraskevi Spatharaki' \\ Despina Hatzisymeon' \\ loannis Miminas' \\ Michael G Alexandrakis ${ }^{1,3}$ \\ 'Hematology Laboratory, Iraklion \\ University Hospital, Iraklion, Greece; \\ ${ }^{2}$ Department of Clinical Chemistry- \\ Biochemistry, ${ }^{3}$ Department of \\ Hematology, School of Medicine, \\ University of Crete, Iraklion, Greece
}

Correspondence: Nikolaos E Androulakis Hematology Laboratory, Iraklion University Hospital, Christou Mpantouva 2, 7।305 Iraklion, Crete, Greece

Tel +30693686 I599

Email nikandgr@yahoo.gr
Aim: To examine whether a high volume of soccer-specific training can lead to endothelial activation and/or dysfunction in professional soccer players due to exercise-induced oxidative stress.

Methods: Twenty-three (15 nonsmokers and eight smokers) healthy, elite male professional soccer players (mean age: $25.2 \pm 4.3$ years, BMI: $23.1 \pm 1.3 \mathrm{~kg} / \mathrm{m}^{2}$, fat: $7.8 \% \pm 2.6 \%$ ) were selected for this study. All participants had a full clinical and laboratory evaluation. von Willebrand factor antigen (vWf Ag) plasma levels were measured on two different occasions: 1 day before the beginning of the preseason preparation period and after 7 weeks of strenuous exercise.

Results: Mean vWf Ag plasma levels were significantly decreased from $95.1 \% \pm 26 \%$ to $88.3 \% \pm 27.2 \%$ at the end of the experimental period $(P=0.018)$, suggesting a potential beneficial effect on the endothelium of these athletes. Further analysis showed that age greater than 29 years with an age range from 29 to 34 years can not impair this effect $(P>0.05)$.

Conclusion: Strenuous exercise did not lead to endothelium activation or dysfunction in well-trained elite soccer players. On the contrary, it seemed to produce a beneficial effect on the endothelium of these players.

Keywords: endothelium, strenuous exercise, smoking

\section{Introduction}

Endothelial dysfunction can be broadly defined as an imbalance between vasodilating and vasoconstricting substances produced by (or acting on) the endothelium. This condition reflects the impaired ability of endothelium cells to participate adequately both in coagulation and fibrinolysis and these changes may predispose to thrombus and atherosclerosis formation. ${ }^{1}$

Endothelial dysfunction can result from and/or contribute to several disease processes, such as hypertension, hypercholesterolemia, diabetes, etc. It can also result from environmental factors, such as smoking and exposure to air pollution. ${ }^{2}$ It is often regarded as a key early event in the development of atherosclerosis. One of the main mechanisms of endothelial dysfunction is considered to be the reduction or the diminishing of nitric oxide (NO), due to impaired production by the endothelium and/ or increased inactivation of NO by reactive oxygen species (ROS). In fact, the most prevailing mechanism of endothelial dysfunction is an increase in ROS, which can impair NO production and activity via several mechanisms. ${ }^{3}$

Several methods have been employed to assess endothelial function. Invasive techniques, which involve intracoronary or intrabrachial infusions of vasoacting agents, are still considered to be the gold standard for early detection of endothelial 
dysfunction. In addition, several noninvasive techniques such as high-resolution ultrasound assessment of endotheliumdependent flow-mediated vasodilation and strain-gauge plethysmography have been developed with comparable results and good reproducibility. An alternative method to assess endothelial function involves the measurement of biomarkers of endothelial activation and dysfunction such as endothelial adhesion molecules like E- and P-selectin and the intercellular adhesion molecule-1 (ICAM-1), vascular endothelial cadherin, growth factors such as angiopoietin-1 and -2 , and vascular endothelial growth factor, as well as von Willebrand factor antigen (vWf Ag), ${ }^{4,5}$

On the other hand, several experimental studies have shown that physical exercise is associated with a reduction of morbidity and mortality among physically active individuals, as compared to sedentary controls, in both health and cardiovascular disease. ${ }^{6,7}$ These findings can be attributed to the fact that low-intensity activity is capable of restoring and improving the endothelial function. In vivo studies in humans and animals have shown that exercise leads to an increased vascular expression of endothelial NO synthase $(\mathrm{eNOS}),{ }^{8,9}$ resulting in higher levels of NO in the endothelium, thus demonstrating the important role that exercise plays in the prevention and treatment of cardiovascular diseases. However, a number of studies showed that localized exercise training does not improve $\mathrm{NO}$ vasodilator function in healthy subjects and evidence of any benefit from larger muscle group exercise is relatively modest. ${ }^{10,11}$ It appears that, for a beneficial effect of exercise training on individuals with normal vascular function, a high volume of exercise may be required.

There are few data available regarding the optimal volume of training which can lead to a beneficial effect on normal epithelium. Published data support that low-intensity exercise may fall below the threshold for improvement in NO-related vascular function and moderate-intensity exercise enhances endothelial NO production, while high-intensity exercise may abolish any NO-induced improvement in vascular function due to interaction and inactivation of endothelial $\mathrm{NO}$ by free radical species generated during high-intensity exercise. ${ }^{12}$ Furthermore, high-intensity endurance training has been linked to reduced endothelial function in moderately well-trained subjects. ${ }^{13}$

The preseason preparation period in soccer is typically characterized by a high volume of training and gradually increased intensity. We hypothesized that increased oxidative stress produced by prolonged exercise training may lead to endothelial activation. Therefore, the objective of this study was to examine whether training during the preseason preparation period can lead to endothelial activation and/or dysfunction in young healthy, elite, professional soccer players.

\section{Methods}

\section{Study protocol}

We evaluated the vWf Ag plasma levels on two different occasions. The first experimental testing took place at the end of a 6-week off-season transition period, 1 day before the beginning of the preparation period. The second experimental testing was performed after 7 weeks, at the end of the preseason preparation period. Each experimental testing consisted of blood sampling and anthropometric measurements (ie, height [cm], body weight $[\mathrm{kg}]$, body mass index [BMI], and body fat percentage).

\section{Participants}

Twenty-three male professional soccer players, members of a Greek Super League team, were initially selected for this study. All players underwent a full clinical assessment, including chest X-ray and echocardiography. Exclusion criteria were: arterial hypertension according to the recommendations of the European Society of Hypertension/ European Society of Cardiology, hyperlipidemia, diabetes type 2 and type 1, history of drug or alcohol abuse, any chronic inflammatory or other infectious diseases during the last 6 months, thyroid gland disease, valvular heart disease, ejection fraction $<55 \%$, history of cardiomyopathy, any kind of medication and/or antioxidant supplements in the last 6 months, and smoking. All athletes were found completely healthy. Eight of them reported that they were light smokers and they were excluded from the study. Finally, the study population consisted of 15 players of mean age $24.9 \pm 5.6$ years, BMI $23.7 \pm 1.2$, and body fat $7.3 \% \pm 2.6 \%$. The age range of the participants was between 18 and 34 years and four of them were over 29 years old (Table 1).

\section{Off-season guidelines and preseason training protocol Off-season period}

The duration of the off-season period in our study was set to 6 weeks. During the first 2 weeks of this period, the players were instructed to abstain from any physical activity. During the last 4-week period, they were instructed to perform aerobic training sessions $(60 \%-80 \%$ of their maximal heart rate) of 30 minutes' duration ( $30,3 \times 10$, and $2 \times 15$ minutes) with 1 day of rest in between. 
Table I Baseline characteristics of the participants

\begin{tabular}{llll}
\hline & Overall & Age $<29$ years & Age $>\mathbf{2 9}$ years \\
\hline $\begin{array}{l}\text { Number of } \\
\text { participants }\end{array}$ & 15 & 11 & 4 \\
Age (years) & & & \\
$\quad$ Mean \pm SD & $24.9 \pm 5.6$ & $22.0 \pm 3.3$ & $32.2 \pm 1.5$ \\
$\quad$ Range & $18-34$ & $18-26$ & $30-34$ \\
Body fat (\%) & & & \\
$\quad$ Mean \pm SD & $7.3 \pm 2.6$ & $7.3 \pm 2.2$ & $7.2 \pm 3.9$ \\
$\quad$ Range & $4.5-13.1$ & $4.5-10.7$ & $4.8-13.1$ \\
Body mass index & & & \\
$\quad$ Mean \pm SD & $23.7 \pm 1.2$ & $23.5 \pm 1.1$ & $24.1 \pm 1.3$ \\
Range & $22.1-25.6$ & $22.1-25.3$ & $22.9-25.6$ \\
\hline
\end{tabular}

Abbreviation: SD, standard deviation.

\section{Preseason period}

During the preseason period, the players participated in 63 training sessions for a period of 7 weeks. These training sessions consisted of 12 technical-tactical training sessions, 15 technical-tactical conditioning sessions (both performed in small-sided game and/or actual match format), eight sprint-agility sessions, nine endurance running sessions, 15 strength conditioning sessions, and eight friendly matches. Weekly training load (TL) was quantified by rating of perceived exertion (RPE), which is highly practical and accurately measures an individual's response (internal TL) to the soccer training and practice. This method of monitoring TL requires each athlete to provide an RPE for each exercise session (Borg RPE Scale) along with a measure of training time (TL equals the session RPE multiplied by the duration in minutes). In our study, the average weekly TL expressed by RPE was 3,735 $\pm 1,396$. The average TL during friendly matches expressed by RPE was $637 \pm 5$.

\section{Specimen collection and preparation}

All participants had a day off from training before each experimental session. Blood samples were collected in the morning after an overnight fast. Blood samples were drawn, through venipuncture using a 21 -gauge needle, and immediately transferred into plastic tubes containing trisodium citrate $3.2 \%$. All samples were transferred to the laboratory and centrifuged for 10 minutes at $1,800 \times g$ within 2 hours. All the platelet-poor plasma samples were stored at $-70^{\circ} \mathrm{C}$ until analysis. On the day of the analysis, the samples were thawed at $37^{\circ} \mathrm{C}$ for 20 minutes and centrifuged again.

Plasma vWf Ag was measured using a latex-particleenhanced immunoturbidimetric assay (Von Willebrand Antigen Kit; Instrumentation Laboratory, Bedford, MA, USA) on an ACL Top coagulation analyzer (Instrumentation Laboratory).

\section{Anthropometric measurements}

Height $(\mathrm{cm})$ was measured using a Seca 206 stadiometer (Seca Vogel, Hamburg, Germany) and weight ( $\mathrm{kg}$ ) was obtained using a Seca 813 high-capacity digital floor scale (Seca Vogel). BMI was calculated as weight over height squared. Body fat percentage was assessed by skinfold thickness measurement (Lange Skinfold Caliper; Cambridge Scientific Instruments, Cambridge, UK) using the four-site formula proposed by Jackson and Pollock. ${ }^{14}$

\section{Nutritional guidelines}

All participants were instructed to avoid any antioxidant supplements like vitamin E, vitamin C, coenzyme Q10, beta carotene, selenium, etc. They were also provided with a daily nutrition plan of 12,500-14,600 kJ with high carbohydrates $(>60 \%)$, low fat $(15 \%-25 \%)$, and low protein $(10 \%-15 \%)$ percentage in order to cover the increased energy needs resulting from strenuous daily training. Finally, they were instructed to maintain good hydration based on their individual sweat rate.

\section{Ethics statement}

Before testing, a verbal explanation was given to all participants, concerning the aim of the study and the testing procedures, and written informed consent was obtained from all of the participants. The study was performed in strict accordance with the ethical guidelines of the Declaration of Helsinki and was approved by the Ethical Scientific Committee of the University Hospital of Iraklion (Iraklion, Greece).

\section{Statistical methods}

Statistical analysis was performed using IBM SPSS Statistics for Windows version 22 (IBM Corporation, Armonk, NY, USA). Continuous variables were expressed as mean \pm standard deviation. Data were initially assessed for normality using the Shapiro-Wilk test $(P>0.05)$ and normal Q-Q plots. The changes in vWf levels between the experimental periods were analyzed using paired samples $t$-test. One-way ANOVA was used in order to evaluate the possible effect of age on vWf plasma levels in the participants. The level of significance was set at $P<0.05$. Analysis was carried out at a confidence interval (CI) of $95 \%$.

\section{Results}

In our study, the mean vWf Ag plasma levels were found to be lower at the end of the experimental period. In fact, at the end of this period, our data showed a reduction of $6.8 \%$ in the mean vWf Ag levels. More specifically, mean vWf Ag 
levels were reduced from $95.1 \% \pm 26 \%$ at the beginning of the preparation period to $88.3 \% \pm 27.2 \%$ after 7 weeks of training. Statistical analysis using paired samples $t$-test revealed that 7 weeks of soccer-specific training during the preseason preparation period led to a significant decrease in vWf Ag plasma levels $(P=0.018)$ compared to baseline. Furthermore, one-way ANOVA showed that, during the experimental period, age greater that 24 years (with an age range between 29 and 34 years) did not significantly impair vWf Ag plasma levels $(P=0.707,95 \% \mathrm{CI})$ in these athletes.

\section{Discussion}

To the best of our knowledge, this is the first study examining the effects of training during the preseason preparation period on endothelium in well-trained, professional soccer players. Our results suggest that soccer-specific training did not lead to endothelium activation or dysfunction in these athletes. On the contrary, the significantly lower vWfAg plasma levels indicate a possible beneficial effect of a high volume of training with gradually increased intensity on vessel endothelium. These findings can be attributed to a potential adaptation to chronic exercise which leads to an attenuation in ROS production.

An increasing body of evidence suggests that oxidant stress inactivates NO and plays a key role in the pathophysiology of endothelial damage. ${ }^{3}$ Exercise training has shown a number of beneficial effects on endothelial function, mostly through effects on bioavailability of NO, increased activity of eNOS and antioxidant enzymes, and activation of matrix metalloproteinase $9 .{ }^{15}$

Depending on its efficacy, the antioxidant system plays a primary role in maintaining ROS below a physiologically compatible threshold level, thus allowing ROS to serve, theoretically, as signaling molecules and preventing them from exerting direct toxic effects. The increased ROS flux occurring in the course of strenuous exercise, through redox-sensitive mechanisms, induces the expression of $\gamma$-glutamylcysteinyl synthetase, the rate-limiting enzyme of glutathione synthesis, of glutathione peroxidase, and of manganese superoxide dismutase. ${ }^{16}$ More particularly, exercise-derived ROS activates nuclear factor-kappaB $(\mathrm{NF}-\kappa \mathrm{B})$, activator protein 1 (AP-1), and mitogen-activated protein kinases (MAPKs) that have been identified as the major signaling pathways directly involved in the induction of the above antioxidant enzymes. ${ }^{16}$ Furthermore, a more recent study by Radovanović et a ${ }^{17}$ investigated the oxidative stress markers in ten young judoists during a 4-week preparatory period training program consisting of strength training, training techniques, and judo fights. Their results indicated that the specific training program did not show any statistically significant effects on the parameters of oxidative stress, concluding that oxidative defense was sufficient in dealing with the oxidative stress.

The literature, so far, has shown conflicting results regarding the influence of exercise on the endothelial markers. For example, there is a study suggesting that exercise training may increase the levels of vWf and sE-selectin, although the latter was not related to the workload or the exercise capacity. ${ }^{18}$ However, the study included in-hospital patients with cardiovascular disease or suspected cardiovascular disease and not healthy well-trained athletes. In addition, it has been reported that acute maximal aerobic exercise doubled plasma vWf in fit subjects but had no effect on the sedentary population. ${ }^{19}$ On the other hand, regular exercise training in stable angina patients following percutaneous coronary intervention may attenuate vWf levels, and this potentially contributes to the beneficial effects of exercise training on restenosis. ${ }^{20}$ In a group of patients with a history of myocardial infarction, 4 weeks of exercise training decreased vWf levels by $16 \% .{ }^{21}$ These contradictory data suggest that several parameters such as endothelial status, training status, and volume and intensity of exercise can significantly influence the effect of exercise training on endothelium. Moreover, this effect can be acute or chronic.

\section{Age and strenuous exercise}

There are numerous studies on animals supporting ageinduced endothelial dysfunction in isolated vessels by several mechanisms. Some suggest that the expression of the eNOS and thus NO production decline with age, ${ }^{22,23}$ while another study has observed an increased eNOS expression during aging. ${ }^{24}$ Finally, some reports also suggest that the cellular antioxidative defense system is attenuated during the aging process, making endothelium more vulnerable to oxidative stress. ${ }^{22,24}$ In our study, analysis revealed that age $>29$ and $<34$ years did not significantly impair the influence of training on endothelium function. This finding can be attributed to the suggestion that the effects of aging on endothelium are not usually noticeable in men until approximately 40 years of age. ${ }^{25}$

\section{Limitations}

Limitations of this study should be noted. First, we used only vWf Ag as a biomarker for the assessment of endothelial function. Although vWf Ag has certainly been associated with endothelial function and vascular health, the determination of more biomarkers like ICAM-1, vascular cell adhesion molecule-1 (VCAM-1), E- and P-selectin, etc, would have 
strengthened our results. Second, our results were not validated with one of the noninvasive techniques that have become available for assessing endothelial function such as flow-mediated vasodilation, strain-gauge plethysmography, etc.

\section{Conclusion}

Our findings suggest that in well-trained elite soccer players, training during the preseason preparation period did not lead to endothelial activation and/or dysfunction. On the contrary, it seemed to produce a beneficial effect on the endothelium, as indicated by the significantly lower vWfAg plasma levels at the end of the experimental period.

\section{Disclosure}

The authors report no conflicts of interest in this work.

\section{References}

1. Boneu B, Abbal M, Plante J, Bierme R. Letter: factor-VIII complex and endothelial damage. Lancet. 1975;1(7922):1430.

2. Münzel T, Sinning C, Post F, Warnholtz A, Schulz E. Pathophysiology, diagnosis and prognostic implications of endothelial dysfunction. Ann Med. 2008;40:180-196.

3. Cai H, Harrison DG. Endothelial dysfunction in cardiovascular diseases: the role of oxidant stress. Circ Res. 2000;87:840-844.

4. Lumachi F, Zanella S, Cella G, Casonato A, Fallo F. Endothelial activation markers soluble E-selectin and von Willebrand factor in primary hyperparathyroidism. In Vivo. 2011;25(2):279-282.

5. Vischer UM, Emeis JJ, Bilo HJ, et al. von Willebrand factor (vWf) as a plasma marker of endothelial activation in diabetes: improved reliability with parallel determination of the vWf propeptide (vWf:AgII). Thromb Haemost. 1998;80(6):1002-1007.

6. O'Connor GT, Buring JE, Yusuf S, et al. An overview of randomized trials of rehabilitation with exercise after myocardial infarction. Circulation. 1989;80:234-244.

7. Hakim AA, Petrovitch H, Burchfiel CM, et al. Effects of walking on mortality among nonsmoking retired men. $N$ Engl J Med. 1998;338: 94-99.

8. Kojda G, Cheng YC, Burchfield J, Harrison DG. Dysfunctional regulation of endothelial nitric oxide synthase (eNOS) expression in response to exercise in mice lacking one eNOS gene. Circulation. 2001;103: 2839-2844.

9. Hambrecht R, Adams V, Erbs S, et al. Regular physical activity improves endothelial function in patients with coronary artery disease by increasing phosphorylation of endothelial nitric oxide synthase. Circulation. 2003; 107:3152-3158.
10. Green DJ, Cable NT, Fox C, Rankin JM, Taylor RR. Modification of forearm resistance vessels by exercise training in young men. $J$ Appl Physiol (1985). 1994;77:1829-1833.

11. Kingwell BA, Sherrard B, Jennings GL, Dart AM. Four weeks of cycle training increases basal production of nitric oxide from the forearm. Am J Physiol. 1997;272(3 Pt 2):H1070-H1077.

12. Bergholm R, Mäkimattila S, Valkonen $\mathrm{N}$, et al. Intense physical training decreases circulating antioxidants and endothelium-dependent vasodilation in vivo. Atherosclerosis. 1999;145(2):341-349.

13. Green DJ, Maiorana A, O'Driscoll G, Taylor R. Effect of exercise training on endothelium-derived nitric oxide function in humans. J Physiol. 2004;561(Pt 1):1-25.

14. Jackson AS, Pollock ML. Generalized equations for predicting body density of men. 1978. Br J Nutr. 2004;91(1):161-168.

15. Ribeiro F, Ribeiro IP, Alves AJ, et al. Effects of exercise training on endothelial progenitor cells in cardiovascular disease: a systematic review. Am J Phys Med Rehabil. 2013;92(11):1020-1030.

16. Gomez-Cabrera MC, Domenech E, Viña J. Moderate exercise is an antioxidant: upregulation of antioxidant genes by training. Free Radic Biol Med. 2008;44(2):126-131.

17. Radovanović D, Bratić M, Nurkić M, Kafentarakis I, Kolias C. Effects of specially designed training on functional abilities and blood markers of oxidative stress in elite judo athletes. In: Hökelmann A, Brummund M, editors. Book of Proceedings of the World Congress of Performance Analysis of Sport VIII. Magdenburg: Otto von Guericke University; 2008:393-397.

18. Boos CJ, Balakrishnan B, Lip GY. The effects of exercise stress testing on soluble E-selectin, von Willebrand factor, and circulating endothelial cells as indices of endothelial damage/dysfunction. Ann Med. 2008;40(1):66-73.

19. O'Sullivan SE. The effects of exercise training on markers of endothelial function in young healthy men. Int J Sports Med. 2003;24(6): 404-409.

20. Munk PS, Breland UM, Aukrust P, Ueland T, Kvaløy JT, Larsen AI. High intensity interval training reduces systemic inflammation in postPCI patients. Eur J Cardiovasc Prev Rehabil. 2011;18(6):850-857.

21. Vona M, Codeluppi GM, Iannino T, Ferrari E, Bogousslavsky J, von Segesser LK. Effects of different types of exercise training followed by detraining on endothelium-dependent dilation in patients with recent myocardial infarction. Circulation. 2009;119(12):1601-1608.

22. Barton M, Cosentino F, Brandes RP, Moreau P, Shaw S, Lüscher TF. Anatomic heterogeneity of vascular aging: role of nitric oxide and endothelin. Hypertension. 1997;30(4):817-824.

23. Csiszar A, Ungvari Z, Edwards JG, et al. Aging-induced phenotypic changes and oxidative stress impair coronary arteriolar function. Circ Res. 2002;90(11):1159-1166.

24. van der Loo B, Labugger R, Skepper JN, et al. Enhanced peroxynitrite formation is associated with vascular aging. $J$ Exp Med. 2000;192(12):1731-1744

25. Seals DR, Jablonski KL, Donato AJ. Aging and vascular endothelial function in humans. Clin Sci (Lond). 2011;120(9):357-375.
Vascular Health and Risk Management

\section{Publish your work in this journal}

Vascular Health and Risk Management is an international, peerreviewed journal of therapeutics and risk management, focusing on concise rapid reporting of clinical studies on the processes involved in the maintenance of vascular health; the monitoring, prevention and treatment of vascular disease and its sequelae; and the involvement of

\section{Dovepress}

metabolic disorders, particularly diabetes. This journal is indexed on PubMed Central and MedLine. The manuscript management system is completely online and includes a very quick and fair peer-review system, which is all easy to use. Visit http://www.dovepress.com/ testimonials.php to read real quotes from published authors. 